\title{
Reforma agrária e desenvolvimento na América Latina: rompendo com o reducionismo das abordagens economicistas ${ }^{1}$
}

\author{
Sérgio Pereira Leite* \\ Rodrigo Vieira de Ávila**
}

Resumo: Apesar das previsões em contrário, a reforma agrária reassumiu uma posição de destaque no debate, nos processos sociais, nas atividades políticas e em alguns programas governamentais no período recente, apresentando-se como uma oportunidade concreta na estratégia de reprodução social de uma parcela não desprezível de famílias camponesas e de trabalhadores rurais que habitam, por exemplo, os países da América Latina. O texto aborda a relação entre o acesso à terra e o desenvolvimento, recuperando as implicações da reforma agrária sobre o crescimento econômico, visto que é justamente a dimensão econômica aquela na qual este tema tem merecido um conjunto maior de críticas do campo conservador. No entanto, a intenção de pensar a democratização da terra como estratégia de desenvolvimento implica em discutir o combate à pobreza e às injustiças sociais, indo além do mero crescimento. Assim, com base na bibliografia especializada e am-

\footnotetext{
* Professor do Curso de Pós-Graduação em Desenvolvimento, Agricultura e Sociedade (CPDA) da Universidade Federal Rural do Rio de Janeiro (UFRRJ). Pós-doutor em Sócio-Economia do Desenvolvimento pela École des Hautes Études en Sciences Sociales (EHESS), Paris, França. Doutor em Economia pela Universidade Estadual de Campinas (Unicamp), Campinas, São Paulo. sergioleite@ufrrj.br

** Mestre pelo CPDA/UFRRJ, Rio de Janeiro. rodeavila@yahoo.com.br

${ }^{1}$ Este trabalho consiste numa versão modificada da primeira parte do estudo, intitulado "Agrarian reform, social, justice and sustainable development" elaborado pelos autores para a Conferência Internacional sobre Reforma Agrária e Desenvolvimento Rural, atendendo ao convite da Organização das Naç̃oes Unidas para Agricultura e Alimentação (FAO/ONU).
} 
parando-se em dados estatísticos, o trabalho tratou de problematizar o tema da distribuição de ativos no atual contexto latino-americano, longe das armadilhas reducionistas que foram impostas ao mesmo pelo pensamento economicista em voga ao longo dos anos 80 e 90.

Palavras-chave: Reforma Agrária; Desenvolvimento Rural; Política Agrária

Classificação JEL: Q 150; $O$ 130; R 140; Q 010

\begin{abstract}
It is necessary to rethink the process of agrarian transformation by approaching agrarian reform as a strategic vehicle for social and sustainable development. This has implications for general agricultural and economic growth, as well as for social justice and the conception of development as an expansion of freedom. Various analytical studies of the economic and historical factors of agricultural development processes, for example in Latin America context, have highlighted a number of important linkages that should be considered in discussions of agrarian reform. High levels of inequality at the beginning of a development process (for example, high concentration of land and wealth) weigh negatively on long-term economic growth. Countries with a high concentration of land achieve slower economic growth than those with a more egalitarian land structure. High levels of economic and land concentration also form a barrier to the promotion of social justice, leaving millions of people in the margins of full citizenship. Agrarian reform programmes should be accompanied by measures such as poverty reduction and equity promotion policies, to support the beneficiaries in order for these reforms to have significant and sustainable results.
\end{abstract}

Key words: Agrarian reform, Rural Development, Agrarian Policy

JEL Classification: Q 150; O 130; R 140; Q 010 


\section{Introdução}

Nos chamados países em desenvolvimento, particularmente naqueles localizados na América Latina, o tratamento dispensado ao tema da reforma agrária tem sido, invariavelmente, acompanhado de declarações calorosas a respeito - contrárias ou favoráveis - nem sempre compatíveis com a necessária elucidação dos fatos e eventos que ilustram os processos sociais, políticos e econômicos que acompanham o assunto no contexto histórico recente. Parte dessas declarações é acionada no sentido de apresentar as distorções - particularmente no âmbito econômico - que um efetivo programa de reforma agrária poderia proporcionar sobre os sistemas agrícolas nessas regiões. A este tipo de crítica juntam-se ainda os argumentos sobre a obsolescência e o caráter inoportuno da democratização da terra no atual estágio dessas sociedades.

Poderíamos especular que essas colocações erguem-se e justificamse a partir de uma herança fundamentada na prática de uma matriz de modernização (técnica) da agricultura em voga nos anos 60 e ao longo de toda a década de 1970, cujos resultados foram objeto de ampla e qualificada crítica. Como afirma Tavares (1996: 5): “da perspectiva do pensamento reformista latino-americano dos anos 50 e 60, a reforma agrária era concebida como um processo social inserido em um movimento global de transformação da sociedade e direcionado a três objetivos estratégicos: a ruptura do poder político tradicional (democratização), a redistribuição da riqueza e da renda (justiça social) e a formação do mercado interno (industrialização). No caso brasileiro, as transformações ocorridas no campo durante as décadas de 1960 e 1970 (...) e o marco político-ideológico que se consolidou (...) conduziram a um progressivo reducionismo na concepção da reforma agrária, que foi redefinida (...) como um instrumento de 'política de terras'. A 'revolução agrícola' (...) 'desativou' o significado econômico clássico da reforma (a formação do mercado interno), contribuindo assim para a afirmação da concepção reducionista”. E segue Maria da Conceição Tavares lembrando que as "transformações das bases técnicas e econômicas" não tiveram correspondência nos outros planos: "a terra e a riqueza continuaram sendo concentradas por força dos novos interesses agroindustriais, da expansão da fronteira e dos interesses agrários 'tradicionais' (...) ". E, depois de lembrar que a terra "mantém (...) 
Reforma agrária e desenvolvimento na América Latina:

rompendo com o reducionismo das abordagens economicistas

notável importância econômica e política", conclui: "a confluência no campo de dois processos - a modernização conservadora da produção e o agravamento dos fatores de exclusão nas áreas tradicionais e de fronteira - tende a tornar mais crítica a questão da terra".

O reducionismo de que nos falava Tavares viu-se, ainda, reforçado na conjuntura das duas últimas décadas, quando uma abordagem mais complexa sobre as transformações do meio rural brasileiro deu lugar ao discurso em prol do produtivismo renovado, agora em bases - financeiras, tecnológicas e institucionais - diferentes daquelas que vigeram ao longo do período anterior, e da forte orientação liberalizante e exportadora imposta à atividade agropecuária como resultado dos ajustes operados nas variáveis de políticas macroeconômicas.

É preciso, portanto, repensar a própria matriz do processo de transformação rural, retirando-o das amarras reducionistas às quais o mesmo foi submetido, alargando, dessa forma, os horizontes do campo de possibilidades e oportunidades sociais e inserindo a reforma agrária, como bem lembrou Furtado (1998), num dos vetores estratégicos do desenvolvimento econômico, social e sustentável.

Para tanto, este trabalho propõe-se a abordar a relação entre o acesso à terra e o desenvolvimento, recuperando as implicações da reforma agrária sobre o crescimento econômico, visto que é justamente a dimensão econômica aquela na qual este tema tem merecido um conjunto maior de críticas do campo conservador. No entanto, a intenção de pensar a democratização da terra como estratégia de desenvolvimento implica em discutir outras dimensões do processo (entre as quais o combate à pobreza e às desigualdades sociais), indo além do mero crescimento. Debruçamo-nos, na seqüência no exame dessas questões, à luz das evidências estatísticas tratadas no primeiro bloco do texto.

\section{Concentração de renda, de terras e a necessidade da reforma agrária}

Hoje, metade da população mundial vive na pobreza, ou seja, com menos de dois dólares por dia. As regiões com maior pobreza são o Sudoeste Asiático e a África Subsaariana, regiões que concentram os 50 países mais pobres (cf. Figura 1) e onde há também grave carência de 
água potável. Na África, de acordo com o Departamento de Referência da População, Washington (2005), a mortalidade infantil é 15 vezes maior que nos países desenvolvidos. Segundo a UNCTAD (2002), nos 49 países mais pobres do mundo, o número de pessoas na extrema pobreza (com renda menor que um dólar por dia) dobrou nos últimos 30 anos, chegando a dois terços da população destes países. Até 2015 este número aumentará ainda mais, em pelo menos 113 milhões, comprometendo o cumprimento das Metas para o Milênio.

\section{Figura 1}

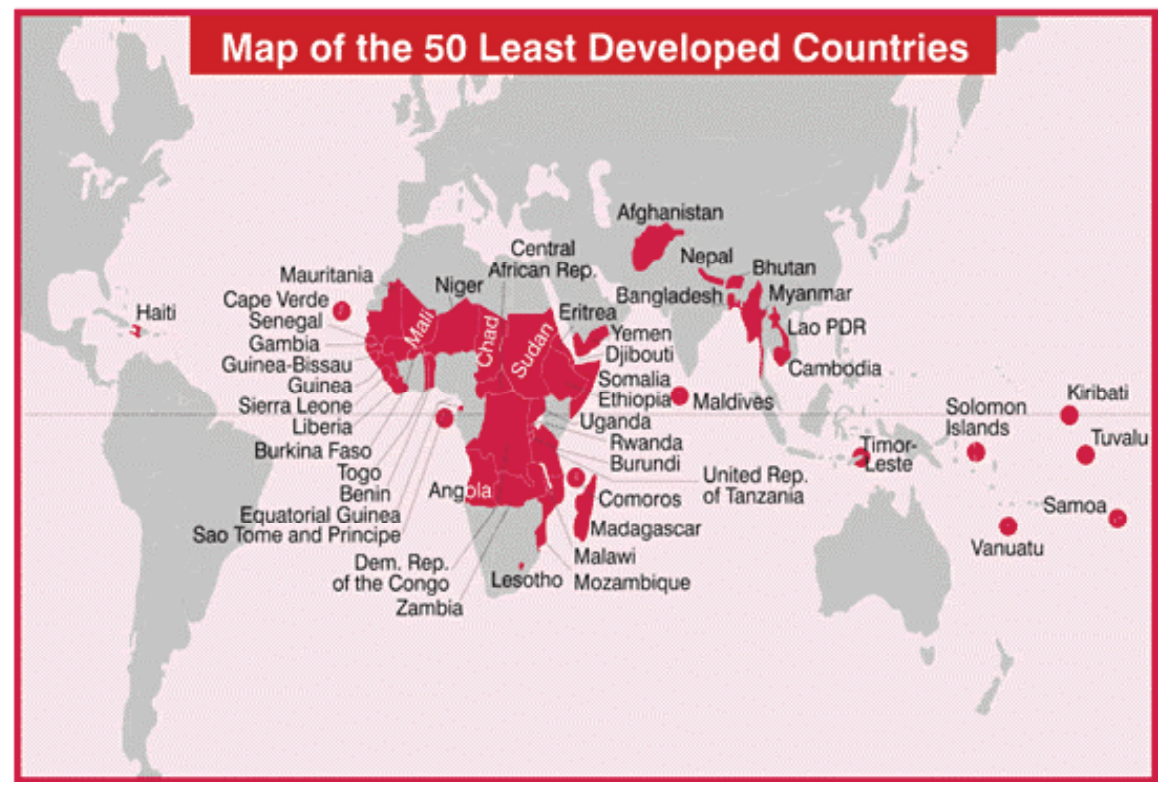

Fonte: UNCTAD

Nos países mais pobres da África - que inclui 34 dos 49 países mais pobres do mundo - quase nove entre cada 10 pessoas vivem com menos de dois dólares por dia, com um consumo médio de 86 centavos diários, em comparação ao consumo per capita de 41 dólares por dia nos Estados Unidos. Nestes 34 países africanos, da segunda metade dos anos 70 até a segunda metade dos anos 90, a proporção de pessoas que ganham menos de um dólar por dia aumentou de $56 \%$ para $65 \%$, ainda segundo a UNCTAD. 
Na América Latina e Caribe, o número de pobres aumentou em 3 milhões desde 1990 - chegando a 96 milhões - nesta região, que também sofre um forte processo de concentração de renda, segundo a Comissão Econômica para a América Latina e o Caribe (CEPAL), em seu Relatório Anual de 2005.

A pobreza no mundo afeta particularmente a população que habita o meio rural, onde encontram-se, segundo a FAO (2002), 3.233 milhões de pessoas, das quais 2.881 milhões estavam concentradas nos países classificados como "em desenvolvimento" (Garcés, 2005). Para uma idéia mais precisa da magnitude desse problema, é possível constatar pelos dados da CEPAL apresentados por Chonchol (2005), a dramática situação latino-americana (cf. Tabela 1). Este autor salienta que, além da drástica redução absoluta do número de pessoas (122 milhões em 1980 para 111 milhões em 1997), a pobreza incide basicamente sobre o segmento de comunidades indígenas camponesas $(30 \%$ do total dos pobres rurais) e pequenos produtores que subsistem em zonas áridas ou semi-áridas da região (outros $30 \%$ ).

Tabela 1. População pobre e extremamente pobre no meio rural América Latina (\%)

\begin{tabular}{l|c|c}
\hline Países & $\begin{array}{c}\text { População rural em condições de } \\
\text { pobreza (\% sobre a população } \\
\text { rural total) }\end{array}$ & $\begin{array}{c}\text { População rural em condições } \\
\text { de extrema pobreza (\% sobre a } \\
\text { população rural total) }\end{array}$ \\
\hline Brasil & 75,5 & 36,5 \\
Chile & 57,1 & 32,6 \\
Colombia & 66,6 & 38,1 \\
Costa Rica & 51,1 & 29,2 \\
El Salvador & 42,8 & 21,4 \\
Honduras & 44,4 & 25,4 \\
México & 78,0 & 44,6 \\
Panamá & 54,8 & 31,3 \\
Peru & 43,3 & 28,9 \\
R. Domicana & 56,3 & 32,2 \\
Venezuela & 86,2 & 49,2 \\
\hline
\end{tabular}

Fonte: CEPAL (1997) apud Chonchol (2005).

Como pode ser visto pelo quadro, países como Venezuela e México possuem quase metade da população rural em situação de extrema 
pobreza, e outros como Brasil e Colômbia concentram parcela significativa dos seus habitantes do meio rural em condições de pobreza, o que acaba repercutindo na capacidade de emprego dessa população marginalizada e no seu acesso aos alimentos. Como é sabido, a fome é, atualmente, um dos principais problemas mundiais, afetando a capacidade de reprodução social de parte significativa da sociedade (Garcés, 2005). Mesmo sem condições de discorrer mais sobre esse assunto, é importante mencionar que dados da FAO apontavam para um número aproximado de 852 milhões de pessoas que passam fome no mundo - 18 milhões a mais que nos anos 1990. Deste total, 815 milhões vivem nos países em desenvolvimento.

Figura 2. América do Sul - Amostra de Países

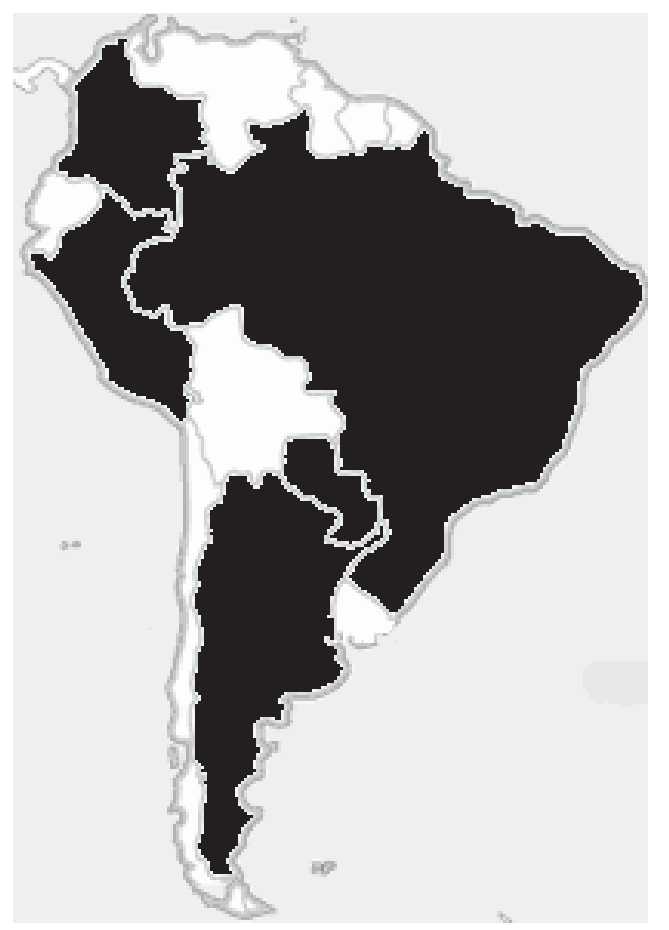

Da mesma forma, podemos observar que, para um conjunto significativo de países, a terra permanece sendo um dos ativos com elevada concentração da sua propriedade, como pode ser constatado por meio 
Reforma agrária e desenvolvimento na América Latina:

rompendo com o reducionismo das abordagens economicistas

dos dados do Censo Agrícola Mundial de 1990, elaborado pela FAO. Trataremos a seguir do caso sul-americano ${ }^{2}$.

Os países que forneceram dados de forma comparável, segundo as estatísticas da FAO, foram: Argentina, Brasil, Colômbia, Paraguai e Peru. Vemos no mapa acima (Figura 2) que estes países (representados em preto) cobrem uma área significativa deste continente. Verificamos igualmente na Tabela 2 , acima, que quase a metade $(46,04 \%)$ dos estabelecimentos agrícolas detém apenas $1,26 \%$ das terras, enquanto $14,64 \%$ dos proprietários detêm $88,68 \%$ das áreas. Se excluirmos o Peru da amostra (cujos dados não se apresentam desagregados para estabelecimentos acima de $50 \mathrm{ha}$ ), verificamos que apenas 1,03\% dos proprietários detêm nada menos que $52,13 \%$ da extensão territorial (Tabela 3 ).

Veremos a seguir, que os países com elevada concentração de terra apresentaram sérias dificuldades para estabelecer um processo de crescimento econômico. O importante a reter, agora, é que tais níveis de concentração econômica e fundiária são impeditivos para a promoção da justiça social, deixando milhões de pessoas à margem do processo de cidadania plena. Nesse sentido, a reforma agrária constitui-se, seguramente, num dos principais mecanismos de política com amplo grau de cobertura e baixo custo de realização para o enfrentamento dessa situação, requerendo para tanto uma base de forças políticas e sociais que a sustentem. No entanto, como bem lembrou Hirschman (1994) a respeito da interação (on and off process) entre os processos políticos e econômicos, tais mudanças requerem a presença de atores estratégicos para sua consecução e as trajetórias assumidas por ambos não necessariamente devem observar um comportamento funcional. Ou seja, é provável que mesmo sendo objeto de uma forte reação contrária, a reforma agrária possa traduzir-se numa medida exitosa, ganhando autonomia em relação aos pressupostos que a fundamentaram, como a distribuição de ativos, passando a se desenvolver de forma sustentável, no sentido amplo da palavra. Na mesma direção, é

${ }^{2}$ Muitos países não divulgaram os dados acerca de distribuição de terras, e alguns divulgaram de forma não padronizada, ou seja, que não permitem a soma com os demais países, dificultando a elaboração de um quadro conjunto. A possibilidade de incluir outros países dessa região provavelmente tornaria o quadro mais dramático. A situação complica-se ainda mais no caso do Censo Agrícola de 2000, onde há uma menor disponibilidade de informações que sejam metodologicamente comparáveis entre diferentes países. 
fundamental que, acoplado ao processo de implementação dessa política redistributiva, seja problematizado o próprio padrão de desenvolvimento que tem pautado a trajetória dos últimos 50 anos dos países em desenvolvimento, questionando a prioridade conferida ao modelo agroexportador (com ou sem industrialização) e aos interesses dos grandes grupos que o embasam e que impedem um desenvolvimento mais justo e equânime dessas nações. O tema será objeto dos próximos itens.

Tabela 3. Estrutura Agrária da América do Sul (Brasil, Argentina, Paraguai e Colômbia)

\begin{tabular}{l|r|r|r|r}
\hline $\begin{array}{c}\text { Tamanho dos } \\
\text { Estabelecimentos }\end{array}$ & $\begin{array}{c}\text { Número de } \\
\text { Estabelecimentos }\end{array}$ & $\begin{array}{c}\text { Área total dos } \\
\text { estabelecimentos } \\
\text { (ha) }\end{array}$ & $\begin{array}{c}\text { Estabelecimentos } \\
\text { (\% do total) }\end{array}$ & $\begin{array}{c}\text { Área } \\
\text { ( do total) }\end{array}$ \\
\hline Até 5 ha & 3.293 .544 & 6.260 .251 & 40,89 & 1,02 \\
De 5 a 10 ha & 1.101 .506 & 7.729 .991 & 13,68 & 1,26 \\
De 10 a 20 ha & 1.106 .075 & 15.269 .969 & 13,73 & 2,49 \\
De 20 a 50 ha & 1.168 .587 & 36.262 .426 & 14,51 & 5,91 \\
De 50 a 100 ha & 582.079 & 40.366 .821 & 7,23 & 6,58 \\
De 100 a 200 ha & 383.095 & 51.455 .443 & 4,76 & 8,39 \\
De 200 a 500 ha & 249.985 & 76.466 .263 & 3,10 & 12,46 \\
De 500 a 1.000 ha & 86.971 & 59.931 .848 & 1,08 & 9,77 \\
Mais de 1.000 & 82.570 & 319.832 .413 & 1,03 & 52,13 \\
\hline TOTAL & 8.054 .412 & 613.575 .425 & 100,00 & 100,00 \\
\hline
\end{tabular}

Fonte: Censo Agrícola Mundial de 1990 - FAO. Elaboração dos autores.

\section{Os anos 90: lições aprendidas e as perspectivas para a reforma agrária}

Se na década de 1980 os países em desenvolvimento se encontraram constrangidos pela crise econômica e pelos ajustes estruturais, na década de 1990 o avanço da hegemonia neoliberal iria pregar, além da continuidade das políticas de ajuste fiscal, o afastamento do Estado da economia. Segundo Cox et al. (2003), isto se traduziu na emergência de propostas como a distribuição das terras realizada via livre-mercado e políticas de privatização de setores prestadores de assistência e apoio aos produtores rurais. Nesta situação, os agricultores - principalmente os pequenos - teriam limitado acesso à assistência necessária para po- 
derem tirar proveito das oportunidades de mercado. No sentido de se analisar as perspectivas futuras da reforma agrária, os autores listam determinadas lições que podem ser aprendidas com o sucesso/insucesso de diversas reformas agrárias realizadas nas últimas décadas. Assim, são descritos vários fatores importantes para estas reformas serem bem sucedidas:

a) presença de um forte aparato governamental, com vontade política e segurança jurídica para os novos donos da terra;

b) política macroeconômica favorável (taxas de juros, câmbio, política agrícola);

c) suporte técnico, organizacional e financeiro aos beneficiários (de forma não centralizada e não burocrática);

d) experiência gerencial dos beneficiários e infra-estrutura previamente disponível;

e) incentivos econômicos aos beneficiários (controle de seu próprio trabalho), apoiando a produtividade e a formação de empresas não agrícolas;

f) compensações para os ex-proprietários, estimulando o investimento em outros setores;

g) formação de capital social, com a participação dos beneficiários na definição de seus destinos;

h) política agrária correta (bons sistemas de registro, planejamento e tributação da terra).

Há divergências entre autores acerca de alguns destes fatores. Segundo Veiga (1991), o sucesso da reforma agrária japonesa em 1947 se deveu ao pagamento de indenizações irrisórias aos ex-proprietários, o que foi fundamental para a desapropriação de um terço da área agrícola do Japão em apenas 21 meses, beneficiando quatro milhões de famílias. Assim, os novos proprietários, em sua maioria ex-arrendatários, teriam estímulo para investirem nas suas terras. Segundo o autor, mais duas importantes reformas agrárias bem sucedidas na década de 1950 (Taiwan e Coréia) também indenizaram os ex-proprietários a valores bem abaixo do mercado. "Nos três casos, houve áspero confisco da base de captação da renda fundiária e sua entrega, quase gratuita, a produtores familiares anteriormente dependentes do jugo dos senhorios" (Veiga, 
1991:148). O autor ainda cita o pagamento de indenizações como entrave à reforma agrária egípcia, também no mesmo período.

El Ghonemy (2005:5-6), comentando sobre as dificuldades colocadas para a realização da reforma agrária nos anos 90, lista três possibilidades para o futuro agrícola mundial: o desemprego rural; a entrega das terras, pelos pequenos proprietários, a especuladores ou rentistas; ou o abandono da política de reforma agrária imposta pelo Estado em favor de uma redistribuição de terras orientada pelo mercado. Por outro lado, uma importante lição aprendida a partir da WCARRD (Conferência Mundial sobre a Reforma Agrária e o Desenvolvimento Rural, promovida pela FAO/ONU em 1979) foi a necessidade de se aumentar os recursos públicos para o desenvolvimento agrário, visto que a demanda por alimentos apresenta crescimento, ao mesmo tempo em que a oferta de terras aráveis decresce continuamente. Assim, ainda segundo o autor, muito mais do que o mero acesso à terra, faz-se necessário o aumento da produtividade e, mais amplamente, a melhoria dos arranjos institucionais de apoio ao desenvolvimento rural.

Algumas condições adicionais para o sucesso das reformas agrárias são listadas pela FAO (2001). Em primeiro lugar, a melhoria tecnológica da agricultura não poderia ser atingida através de técnicas capital-intensivas, visto que muitos pequenos agricultores não teriam como dispor de capital para adotá-las. Uma estratégia de desenvolvimento desta natureza também não geraria emprego, afetando os encadeamentos de demanda com o setor não-agrícola. Os insumos deste tipo de agricultura também seriam largamente importados de outras regiões e o padrão de consumo dos agricultores mais capitalizados demandaria bens de alto valor, de luxo, não produzidos localmente. Os encadeamentos de demanda (intermediária e final) da agricultura seriam então desviados para fora da região. Por outro lado, a estratégia de crescimento agrícola baseada em técnicas trabalho-intensivas permitiria o acesso dos agricultores a essas técnicas, possibilitando que os trabalhadores e produtores rurais mais pobres se beneficiassem, e gerando assim encadeamentos de demanda final e intermediária no setor não-agrícola local.

Sarris (2001) também faz um apanhado de experiências históricas de diversos países que trilharam este caminho. No Japão, desde o início do século, a melhoria tecnológica da agricultura, ao contrário de 
Reforma agrária e desenvolvimento na América Latina:

rompendo com o reducionismo das abordagens economicistas

outros países, provocou aumento na produtividade da mão-de-obra, gerando renda para os agricultores individuais, e subseqüentes estímulos a pequenas indústrias de base rural. Na Índia, o desenvolvimento agrícola calcado no emprego fez a pobreza deste país cair à metade em 20 anos, através também do estímulo da demanda agrícola à criação de empresas rurais de pequena escala, produtoras de bens não-agrícolas trabalho-intensivos, que aproveitaram a disponibilidade de uma mão-de-obra abundante e subempregada. Processo parecido ocorreu na China, por meio de melhorias tecnológicas, da reforma do sistema de propriedade da terra - com a transformação das propriedades coletivas em um sistema de pequenas propriedades familiares, pelo chamado "Sistema de Responsabilidade Familiar", que gerava mais incentivos à produção agrícola - e da melhoria da infra-estrutura e educação rurais (Amin, 2005). As rendas crescentes dos agricultores eram aplicadas em bens produzidos por indústrias locais de base rural que empregavam intensivamente mão-de-obra. Como resultado, o país passou de $250 \mathrm{mi}-$ lhões de pessoas absolutamente pobres em 1978, para 125 milhões em 1985, e 100 milhões em meados dos anos 90 (Mellor, 2001).

Mellor (2001) também elenca uma série de exemplos dos efeitos do crescimento agrícola nas diversas economias. Analisando o caso de Taiwan, descreve que o desenvolvimento agrícola neste país teria três impactos principais na economia como um todo: a redução da pobreza, a criação de recursos transferidos para o financiamento da industrialização, e a criação de demanda para a produção de indústrias de pequena escala que, inicialmente, serviriam à agricultura, mas, progressivamente, passaram a suprir as cidades e, finalmente, o exterior. Ainda hoje, a maior parte das exportações taiwanesas provém de firmas pequenas (de até 50 empregados), dispersas pelo interior do país. O caso taiwanês também é um exemplo de como ocupações rurais não-agrícolas podem catalisar este processo (Fei, Ranis e Kuo, 1979).

$\mathrm{O}$ autor destaca Bangladesh como um país que experimentou significativa redução de pobreza derivada de uma estratégia de desenvolvimento agrícola. A Malásia também seria um exemplo de como uma política de desenvolvimento agrícola com ênfase nas pequenas propriedades pode gerar crescimento na economia como um todo. Este crescimento foi documentado por Hazell e Roell (1983), que encon- 
traram multiplicadores grandes, retratando a forte influência do crescimento agrícola na economia em geral. Por fim, o autor cita outros exemplos de sucesso da estratégia de crescimento econômico baseado no crescimento agrícola, como a Indonésia, Quênia e Costa Rica - que, contrariamente aos demais países da América Latina, não apresentaram uma excessiva concentração das terras. O autor coloca a importância de fatores como melhorias de infra-estrutura e educação rural para o sucesso de todas as experiências analisadas.

Já Saraceno (2001), ao analisar as lições que a América Latina poderia tirar da experiência da Política Agrícola Comum (PAC) da União Européia, ressalta a necessidade do desenvolvimento rural ser pensado não apenas em sua dimensão setorial (agropecuária), mas conjugado a um enfoque territorial que considere a emergência de atividades rurais não-agrícolas. Segundo a autora, a aplicação de políticas condizentes com este enfoque, com a participação de atores locais na discussão das prioridades regionais, gera um desenvolvimento menos dependente de subsídios e gerador de maior dinamismo a longo prazo. Empreendimentos familiares locais - não necessariamente agrícolas - criam condições para um desenvolvimento endógeno, com maior geração de empregos, e de novas iniciativas empresariais.

O que é retomado por Veiga (2001), quando questiona os resultados do Censo Demográfico realizado em 2000 no Brasil, afirmando que, embora este indique uma aparente urbanização do país, há pequenos municípios rurais que desenvolvem atração populacional, devido à habilidade de suas prefeituras na criação de programas sociais. Estas ações, principalmente em áreas como saúde, educação e infra-estrutura, geram muitos empregos, estimulando a instalação de negócios locais como artesanato, agroindústria, e serviços. Com base nisto, a exemplo da autora anterior, também propõe a discussão do desenvolvimento regional através da iniciativa de grupos locais, que tomariam a forma de "Contratos Territoriais de Desenvolvimento", a serem firmados entre o governo e tais grupos, também enfatizando, com isto, o abandono da visão "setorial" em prol da territorial ${ }^{3}$.

${ }^{3}$ Ainda nessa mesma direção ver também o trabalho da FAO (2004), onde há, inclusive, uma proposta de negociação de políticas no plano territorial. 
Reforma agrária e desenvolvimento na América Latina:

rompendo com o reducionismo das abordagens economicistas

O Programa de Ação definido na WCARRD tinha como princípio o fato de que a transformação da vida rural deve ser buscada por meio de políticas que atinjam o crescimento com equidade, redistribuição do poder econômico e político, e participação popular. Nota-se, portanto, que a Conferência pressupunha que a equidade seria um fator importante na geração do desenvolvimento e que tal redistribuição não deve se limitar a fatores econômicos, mas também políticos. Stiglitz (2000), na mesma direção, afirma que a realização de uma reforma agrária somente lograria êxito caso esta se realizasse em um âmbito mais amplo, fornecendo aos mais pobres não apenas o acesso à terra, mas também ao crédito, à extensão rural e outros serviços. O que, por conseqüência, redundaria numa distribuição do poder político, um maior sentimento de eqüidade e justiça social, e assim uma maior disposição da sociedade para as mudanças necessárias para o processo assim chamado de desenvolvimento. Na literatura, há diversas referências a estas relações, que descreveremos a seguir.

\section{Distribuição de ativos, reforma agrária e crescimento econômico}

Anand e Kanbur (1998) desenvolvem uma análise fundada na distribuição de terras, que correlacionam positivamente à distribuição de renda, verificando que a desigualdade inicial é um fator limitante para o crescimento subseqüente, uma vez que apenas dois de 15 países em desenvolvimento pesquisados com índice de Gini da distribuição de terras superior a 0,7, apresentaram crescimento da riqueza acima de 2,5\% ao ano, no período de 1960 a 1992. Como explicações para esse desempenho, os autores arrolam a limitação da oferta de crédito para os mais pobres (que não disporiam de bens para oferecer como garantia dos empréstimos, deprimindo o investimento) e a baixa escolaridade em uma economia desigual. A distribuição dos ativos fundiários também conduziria a um maior acesso à informação por parte dos agricultores, bem como a novas oportunidades de investimentos produtivos. A hipótese de Kuznets (1955), apoiada em dados restritos a somente três países (EUA, Inglaterra e Alemanha) teria suas premissas rejeitadas tanto nos países em desenvolvimento, como até mesmo em países desenvolvidos. 
Sarris (2001) também sustenta que uma distribuição de terras, com a garantia e especificação clara dos direitos de propriedade, permite que os agricultores possam realizar maiores investimentos nas suas parcelas, como, por exemplo, mudanças técnicas que possam vir a aumentar o valor da propriedade. $\mathrm{O}$ acesso à posse de ativos fundiários por trabalhadores sem-terra poderia igualmente viabilizar outros ganhos de eficiência, como a utilização de diversos recursos produtivos subutilizados (por exemplo, a própria força de trabalho familiar), e a redução do custo do uso dos chamados fatores de produção (por exemplo, a utilização do trabalho familiar, desprovido de custos de supervisão e de transação).

Argumentando que, com a posse da terra garantida os agricultores podem investir e inovar mais do que se apenas fossem meeiros, Stiglitz (2000) acena, ainda, para o desenvolvimento de práticas ecologicamente corretas (evitando a erosão do solo, por exemplo). Os contratos de arrendamento implicariam em custos de agenciamento, isto é, de elaboração e, principalmente, de fiscalização do cumprimento, pelo agricultor sem-terra, dos termos especificados no acordo. A obrigação de entregar ao proprietário uma parte da produção também desestimula o meeiro a produzir mais, com maior esforço e tecnologia que possam vir a melhorar a produtividade da terra a longo prazo. O mesmo autor ressalta, adicionalmente, que o papel da distribuição de terras no desenvolvimento reflete-se não só a partir da melhoria da eficiência econômica pura e simples, mas na distribuição do poder político que decorreria de reformas agrárias bem sucedidas. Estas reformas induziriam uma maior participação popular na formulação das políticas públicas e no quadro de instituições locais, melhorando os resultados das políticas sobre o desenvolvimento. Leite (2000), na mesma direção, aponta que a distribuição de terras também geraria um "aprendizado organizativo" por parte dos agricultores, proveniente da experiência com a luta pela terra e dos procedimentos de constituição das novas unidades produtivas. Há a formação de cooperativas e associações de produtores, o que contribuiria para um maior processo reivindicativo local. Tal processo também teria efeitos benéficos sobre a organização da produção e comercialização agrícola. Hirschman (1984) lembra apropriadamente que, mesmo enfrentando situações temporariamente compreendidas como fracassadas (especialmente tendo em vista a precariedade na qual tais 
Reforma agrária e desenvolvimento na América Latina:

rompendo com o reducionismo das abordagens economicistas

processos sociais se manifestam), as mesmas cumprem, em momento posterior, um papel fundamental para o êxito de projetos que envolvam um mínimo de coletividade. Processo que o autor denominou como o "princípio da conservação e mutação da energia social".

Birdsall e Londono (1997), utilizando a mesma base de dados de Deininger e Squire (1996), avaliaram que, em uma série de 43 países, os maiores níveis iniciais de desigualdade (como, por exemplo, da distribuição de terras e de capital) afetam negativamente o crescimento econômico de longo prazo. Comparando os países do Leste Asiático com os da América Latina, constatou-se que, nas décadas de 1970 e 1980, estes últimos apresentaram crescimento econômico equivalente a apenas $20 \%$ do crescimento dos asiáticos, e boa parte disto seria devido às diferentes distribuições iniciais de ativos entre estas economias. Segundo os autores, se as economias latinas tivessem a mesma distribuição de ativos que as asiáticas em 1960, teríamos somente metade dos pobres que temos hoje. Birdsall et al. (1995), na mesma direção, realizaram um estudo que contrapôs o círculo virtuoso ocorrido no Leste Asiático, caracterizado pelo investimento em educação e desenvolvimento baseado em atividades trabalho-intensivas, com o círculo vicioso da América Latina, aonde prevaleceu a baixa qualificação da mão-de-obra. E, segundo Khan e Muqtada (1997), a elasticidade do emprego com relação ao crescimento da produção, para o período de 1971 a 1992, seria de 0,5 na Ásia, comparado ao resultado de -0,5 na América Latina, o que teria implicado em ainda mais concentração de renda neste continente.

Benabou (1997) também questionaria a idéia original de Kuznets, realizando um estudo empírico sobre 13 países nos anos 90, no qual constatou que a desigualdade teria uma influência negativa no crescimento, gerando instabilidade macroeconômica e constrangendo a poupança e o investimento dos segmentos mais vulneráveis.

Veiga (1998) reúne, igualmente, diversos estudos que comprovam o elo entre distribuição de renda e crescimento econômico mostrando que, inversamente à hipótese de Kuznets (1955), "o crescimento alavancado por um determinado setor da economia só pode ser durável se os benefícios do surto inicial forem distribuídos de maneira suficientemente igualitária que permitam a expansão e o aprofundamento dos mercados" (Veiga, 1998). Uma maior distribuição de renda conduziria 
a uma ampliação dos mercados consumidores, possibilitando, em diversos casos, a constituição de um setor industrial de maior escala, rebatendo positivamente no crescimento. Tal conclusão foi confirmada pelo teste empírico de Anand e Kanbur (1998). Ainda sobre o mesmo campo de argumentações, Guanziroli (1998) lista diversos trabalhos que demonstram, salvo raras exceções, a inexistência de economias de escala na agricultura ${ }^{4}$, o que sustentaria o fato de que a concentração da terra não faria, via rendimentos de escala, aumentar a produção, e, por conseguinte, o crescimento econômico. Mazoyer e Roudart (2002) enfatizam esse mesmo ponto. Apesar de somente os grandes proprietários possuírem grandes equipamentos e máquinas, o acesso dos pequenos a estes implementos é viabilizado pelo mercado de aluguel e pela compra comunitária de máquinas (Binswanger, Deininger e Feder, 1995). Por outro lado, as grandes empresas agrícolas possuem custos de supervisão e gestão da produção que na agricultura, diferentemente da indústria, são altos, quando se contrata vários trabalhadores. Custos de supervisão inexistentes no caso da agricultura familiar, visto que neste caso os trabalhadores participam dos lucros. Não haveria também, custos com contratação e busca de trabalhadores neste último caso.

Segundo Binswanger, Deininger e Feder (1995), a única forma de se ter, em determinado país, a preponderância de grandes propriedades é a partir de políticas públicas que favoreçam estes segmentos, através de subsídios e elementos que auxiliem a melhor inserção no mercado destas grandes unidades produtivas. Tais distorções ocasionadas pela intervenção estatal equivocada levam à pobreza, à estagnação econômica, e à formação de uma economia agrícola de baixa produtividade ${ }^{5}$.

Quando consideramos os efeitos da distribuição de ativos sobre o crescimento econômico, via diminuição de pobreza, várias abordagens

\footnotetext{
${ }^{4}$ Lund e Hill (1979) afirmam que existe um tamanho ideal para as propriedades rurais, cujos rendimentos de escala operariam até um determinado tamanho do imóvel, além do qual passariam a prevalecer retornos decrescentes, com base no aumento dos custos com supervisão e gestão.

${ }^{5}$ Ou ainda, de acordo com Guanziroli (1998): “as políticas públicas, sob o manto de todo tipo de subsídios e facilidades dados aos grandes proprietários, têm efetivamente contribuído para alterar o formato ideal das propriedades e sua forma de gestão na América Latina. (...) Têm sido os subsídios ao crédito e os incentivos fiscais, aliados aos baixos salários, os que, ao compensar os riscos da natureza e a baixa rentabilidade natural da agricultura, permitiram a sobrevivência e expansão das unidades patronais extensivas".
} 
Reforma agrária e desenvolvimento na América Latina:

rompendo com o reducionismo das abordagens economicistas

também podem ser lembradas. Segundo Sarris (2001), a incidência de pobreza extrema na população rural poderia criar "armadilhas de pobreza", aonde a necessidade de se dispor de uma poupança de emergência (que tomaria a forma de investimentos em bens que podem ser vendidos facilmente, como estoques de alimentos, jóias) para enfrentar eventuais choques adversos poderia levar os mais pobres a evitar investimentos mais produtivos, como poços, equipamentos de irrigação, uma vez que estes seriam de liquidação mais difícil em um momento de crise. Isto faz com que investimentos feitos pelos mais pobres não sejam tão produtivos como seriam se estes não necessitassem de tais "reservas de emergência". A incidência de choques adversos pode também levar os chefes das famílias a retirarem seus filhos da escola para trabalharem na agricultura, o que reduz a qualificação da mão-de-obra. Em suma, uma distribuição de riqueza que atacasse tais vulnerabilidades dos mais pobres, gerando-lhes garantias em eventuais crises, aumentaria o crescimento econômico subseqüente.

A redução da pobreza e a promoção da justiça social, com uma melhor condição nutricional das famílias rurais, traduzem-se também em maior crescimento econômico, o que é analisado por Arcand (2000). Haveria uma forte ligação - testada estatisticamente - entre a melhoria da condição nutricional e o crescimento, através do aumento da produtividade da mão-de-obra. Segundo o autor, o impacto de uma melhoria nos níveis nutricionais no crescimento seria sentido principalmente nos momentos em que a desnutrição é mais aguda, fazendo com que a redução da pobreza extrema seja altamente compensadora em termos econômicos.

Lipton (2001) afirma que há uma complementaridade entre determinados fatores, como acesso à saúde, educação e nutrição, sendo estes, se reunidos, fortes condicionantes para que possa haver o aumento da produtividade na agricultura, especialmente pelos mais pobres. Desta forma eles poderiam também participar mais da discussão e da implementação das prioridades do orçamento público, com efeitos benéficos sobre a produtividade. Mas estes fatores só podem ser transformados em desenvolvimento econômico se houver também a disponibilidade de ativos produtivos, como a terra, nas mãos destes produtores para que eles possam transformar estas primeiras conquistas (educação, nutrição, saúde) em desenvolvimento. Tratando especificamente da refor- 
ma agrária, o autor acrescenta que o processo beneficiaria também os trabalhadores rurais assalariados - visto que as pequenas propriedades empregam mais trabalhadores - além de setores locais não agrícolas, na medida em que a renda dos pequenos agricultores é gasta preponderantemente em bens trabalho-intensivos, produzidos em setores rurais não-agrícolas locais.

\section{Para além do crescimento econômico: redução da pobreza e combate à desigualdade}

Em estudo sobre a América Latina, De Janvry e Sadoulet (1999) avaliam que o crescimento econômico apenas reduzirá a pobreza rural e urbana se os níveis iniciais de desigualdade e pobreza não forem muito altos. Nos países nos quais há, no início do processo, uma grande desigualdade, o crescimento é completamente ineficaz no combate a este tipo de injustiça social. Nas cidades, a taxa de escolaridade necessita ser alta para que o crescimento reduza a pobreza. Um outro condicionante para que o crescimento reduza a pobreza/desigualdade é que não haja períodos de recessão, visto que, na análise dos autores, um só ano de depressão econômica anula os efeitos desta redução com base em mais de um ano de crescimento econômico. Outro aspecto a considerar, como vimos, é a redistribuição de ativos para os mais pobres, e a igualdade de oportunidades no acesso a instituições públicas e privadas.

Invertendo a análise, os mesmos autores (idem, 2001) destacam a importância da distribuição da riqueza para o crescimento, afirmando que a pobreza rural na América Latina implica em uma subutilização de recursos econômicos. Caso houvesse uma razoável distribuição de ativos no meio rural, poder-se-ia aproveitar muito melhor a mão-deobra e as terras, e ainda se minimizaria outros problemas que deprimem o crescimento, como o êxodo rural exagerado, a desestabilização política e a deterioração ambiental. Segundo os autores (idem, 2002), nos últimos 30 anos, mais de $75 \%$ da redução da pobreza rural latinoamericana se deveu às migrações, e não ao aumento da renda agrícola. Isto apenas desloca a pobreza para os grandes centros urbanos, onde são recriados os mesmos problemas da pobreza rural.

De Janvry e Sadoulet (2002) listam lições aprendidas após 70 anos de 
reformas agrárias na América Latina. Para eles, a reforma agrária se faz necessária devido à herança colonial deste continente, onde prevalece a grande concentração de terras e os latifúndios, muitos deles estabelecidos sobre territórios indígenas. Primeiramente, os autores comparam a reforma agrária com outras formas de redução da pobreza. Se, por um lado, a migração apenas desloca a pobreza rural para as cidades, e os programas de transferência de renda, apesar de serem de fácil administração, não resolvem a questão estrutural, especialmente de países com grande incidência de pobreza, a reforma agrária e a pluriatividade (propriedades rurais voltadas também para atividades não agrícolas) são vistas como políticas que poderiam reduzir significativamente este problema. Porém, estas duas alternativas têm sido subutilizadas, devido à falta de vontade política.

Um importante condicionante para o sucesso de reformas agrárias é aliar a distribuição de terras a um conjunto de políticas que garantam a competitividade dos seus beneficiários, o que não ocorreu na maioria dos casos na América Latina. Nas reformas peruana e boliviana, os beneficiários não tiveram acesso a estas políticas, enquanto no caso mexicano, houve redução nos investimentos públicos. No Chile, a falta de acesso ao crédito levou parte do público atendido a vender suas terras. Uma importante lição seria, portanto, a necessidade de se adotar políticas de desenvolvimento rural e regional, no sentido também de fomentar, ou pelo menos não inibir, as atividades não-agrícolas correlacionadas aos assentamentos rurais.

Outro aspecto a ressaltar é a importância do instrumento da desapropriação, pelo descumprimento da "função social da terra" especialmente onde há uma grande concentração de terras subutilizadas, e grande concentração de pessoas sem-terra ${ }^{7}$. De Janvry e Sadoulet afir-

${ }^{6} \mathrm{O}$ cumprimento da função social da terra consiste, segundo a legislação vigente em alguns países, na obtenção, por seu proprietário, de requisitos econômicos (produtividade), sociais (como, por exemplo, a concessão de direitos trabalhistas aos assalariados) e ambientais.

${ }^{7}$ Por outro lado, De Janvry e Sadoulet $(2001,2002)$ também afirmam que outras formas de acesso à terra - além da desapropriação - podem ser importantes, como a distribuição de terras públicas, assistência à compra e aluguel de terras, dentre outros. Dado que o tema é bastante controverso, vale aqui a ressalva de Borras Jr. (2006), de que estes últimos instrumentos não devem ser confundidos com um efetivo programa de reforma agrária. 
mam ainda que reformas agrárias incompletas, que não garantiram inteiramente os direitos de propriedade dos seus beneficiários, não permitiram o acesso ao crédito e ao investimento, comprometendo em parte o desenvolvimento dessas novas unidades. Esse aspecto é compartilhado também por Borras Jr., Kay e Lodhi (2005), que de posse de um vasto conjunto de análises sobre diferentes casos nacionais ${ }^{8}$, afirmam que os resultados do programa de reforma agrária, caso não estejam acompanhados de medidas de apoio aos beneficiários podem reduzir, ou mesmo anular, os efeitos da política sobre a redução da pobreza e promoção da equidade. Para De Janvry e Sadoulet (2005), o acesso à terra é fundamental para o desenvolvimento econômico, redução da pobreza e também para a melhoria da sustentabilidade ambiental. A terra não é apenas um fator de produção, mas de riqueza, prestígio e poder. Assim, a sua distribuição ocasionaria não apenas um aumento dos ativos econômicos detidos pelos mais pobres, como também o aumento no poder político e na participação social destes últimos. E devido ao fato de ser também um ativo natural, a distribuição das terras também afeta a sustentabilidade ambiental ${ }^{9}$. Assim, a ligação entre o acesso à terra e o desenvolvimento seria bastante complexa.

$\mathrm{Na}$ terminologia mais afeita aos economistas mais ortodoxos, o acesso à terra também é lembrado como um importante condicionante para a segurança alimentar, a partir do momento em que as falhas de mercado de alimentos tornam muito mais onerosas a compra de artigos alimentícios (De Janvry et al., 2001). Além do mais, neste mercado

\footnotetext{
${ }^{8}$ Foram abordados os casos do Brasil, Bolívia, Vietnam, Filipinas, Armênia, Uzbequistão, Namíbia, Etiópia, Egito e Zimbábue.

${ }^{9}$ As atividades voltadas para a sustentabilidade ambiental também ganham destaque, na medida em que os agricultores executam serviços como reflorestamento, conservação do solo e distribuição de água. Porém, deve haver incentivos para os agricultores implementarem estas ações, cujos custos são concentrados, entretanto seus benefícios se estendem aos agentes econômicos externos. Outros fatores importantes são, ainda, listados por De Janvry e Sadoutet (2002), como a existência de "fundos de emergência" que protegem as famílias contra riscos das atividades econômicas. Um exemplo é a Previdência Rural no Brasil (Delgado e Cardoso, 2000). No entanto, vale a advertência de que a vigência de tais programas, quando empregados como substitutos - e não como medidas complementares - da reforma agrária, não altera o quadro da estrutura fundiária e reduzem os efeitos sobre o processo de desenvolvimento social e econômico, como parece ter ocorrido em alguns casos da África Meridional, segundo Moyo (2005).
} 
Reforma agrária e desenvolvimento na América Latina:

rompendo com o reducionismo das abordagens economicistas

não há perfeita informação sobre a qualidade dos alimentos. Assim, a produção própria de alimentos garante não só a quantidade como a qualidade da alimentação pelos que obtém acesso à terra.

Em outros termos, poderíamos acrescentar, concordando com Leite (2004), que o resultado do acesso à terra é a segurança contra choques de preços de alimentos, instabilidade cíclica da produção e do rendimento agrícola e situações adversas nos mercados de trabalho. A produção própria de alimentos e a garantia de emprego em sua própria terra reduzem a possibilidade de que os agricultores familiares sofram de fome ou desemprego, contribuindo para o papel estratégico do autoconsumo.

As posições favoráveis à implementação de um efetivo programa agrário têm renovado o estoque de argumentos que sinalizam para o potencial transformador da democratização do campo, seja por meio da ampliação da condição de cidadania de uma vasta parcela da sociedade ainda hoje marginalizada, seja por meio do aumento do emprego e da renda rural, da redinamização de diversas regiões geográficas etc.

As questões relacionadas ao emprego, à produção e à renda não estão necessariamente relacionadas ao combate à pobreza. Isto é, o crescimento econômico (entendido aqui como o aumento da produção e/ou da renda e, conseqüentemente, do emprego) não garante necessariamente, como vimos, o desenvolvimento (econômico, social, sustentável etc.), ainda que para que tenhamos desenvolvimento é necessária alguma dose de crescimento. Na realidade, tomados alguns casos latino-americanos, não é possível concluir de que se tratam de países extremamente pobres (especialmente quando comparados, nesse quesito, a outros tantos em situação bem mais vulnerável), ainda que existam no interior dessas nações regiões onde a pobreza e a miséria (rural ou urbana) grassam impunes. No entanto, podemos afirmar categoricamente, com base num vasto arsenal de estatísticas sobre os mais distintos setores que, por exemplo, o Brasil é, sim, um país profundamente injusto. Isto é, os índices de concentração econômica (da renda, da terra, da produção etc.) são extremamente elevados. Nesse sentido o modelo do chamado "agronegócio" tem aprofundado essa desigualdade, na medida em que seu vetor de crescimento é acompanhado por um forte processo de concentração (do crédito, da terra, do espaço etc.), além de uma brutal ocupação de áreas de preservação e/ou de comu- 
nidades nativas (pequenos produtores, índios, extrativistas etc.) com a expansão das monoculturas.

Como demonstrado por uma série de estudos especializados, os efeitos e as mudanças locais proporcionados pela criação dos assentamentos rurais, ou na regularização da posse de camponeses e trabalhadores anteriormente ameaçados, essas novas unidades produtivas e de moradia vem rebatendo em transformações de ordem econômica, política e social que atingem a população beneficiária e envolvem outros atores e instituições locais. Segundo Heredia et al. (2005), Leite et al. (2004) e Medeiros e Deere (2005), no caso brasileiro a reforma agrária gerou efeitos positivos no plano municipal, como a diversificação da produção agrícola, a expansão do mercado de trabalho e o fortalecimento político dos beneficiários, cujas demandas por infra-estrutura física e social não podem ser facilmente ignoradas. A partir do momento em que recebem uma parcela de terra, as famílias começam a ter acesso a outros tipos de benefícios, como créditos para a construção de casas e plantio, que possuem também efeitos-demanda sobre o restante da economia. Outro efeito institucional importante do processo de reforma agrária foi o estabelecimento de um diálogo entre o poder público com setores sociais antes jamais atendidos, alterando-se as tradicionais relações de clientelismo dominantes no meio rural brasileiro.

Num cenário de arrefecimento das oportunidades de trabalho, que tem marcado a conjuntura de diferentes países em desenvolvimento (e também dos países ditos desenvolvidos), os assentamentos representam, adicionalmente, uma importante alternativa de emprego. Segundo Leite et al. (2004) e Medeiros e Leite (2004), além de criar, em média, três ocupações por unidade familiar no próprio estabelecimento, exclusive as atividades desenvolvidas fora do lote, os projetos de reforma agrária também geram trabalho para terceiros, quando se considera a contratação de mão-de-obra externa pelos assentados em 36\% dos lotes pesquisados num desses estudos.

Assim, em diversos casos, o caráter inovador das experiências locais de assentamento será crucial para garantir a expansão das capacidades (humanas inclusive) e ações desses novos protagonistas, movimento que poderá facilitar a definição de estratégias voltadas ao desenvolvimento, se quisermos ficar, por exemplo, com uma referência da noção 
Reforma agrária e desenvolvimento na América Latina:

rompendo com o reducionismo das abordagens economicistas

de desenvolvimento proposta por Sen (2000). Nessa direção, a idéia de assentamento enquanto um mecanismo de acesso aos ativos fundiários, às políticas públicas específicas (como o crédito rural, por exemplo), aos mercados de produtos, consumo e trabalho, aos equipamentos sociais etc., constitui, ela própria, num determinado tipo de impacto e resultado. Comparadas à situação presente e pretérita das famílias assentadas, e guardadas a forte heterogeneidade entre os projetos e a precariedade da infra-estrutura prevalecente em boa parte dos mesmos, poderá ser facilmente constatada uma melhoria nas suas condições de vida. Quando essas oportunidades desembocam na conformação de regiões que abrigam um número considerável de projetos e famílias configura-se, na prática, a constituição de áreas reformadas, contrapondo-se à lógica de desapropriações isoladas que têm caracterizado a intervenção do Estado na questão agrária. Esse aspecto em si é um efeito relevante das transformações que os assentamentos têm provocado no espaço regional, pois potencializa, em função desta concentração de beneficiários, as mudanças anteriormente apontadas.

\section{Considerações Finais}

$\mathrm{O}$ argumento que desenvolvemos neste trabalho, tendo como base autores com distintas filiações teóricas, contrasta consideravelmente com a dimensão residual e compensatória na qual o pensamento conservador, na melhor das hipóteses, confinou o tema do acesso à terra. Para tanto, apoiando-se basicamente na literatura especializada sobre o tema, buscamos apresentar as evidências que permitem afirmar uma causalidade positiva entre distribuição de ativos fundiários e crescimento econômico, sob determinadas circunstâncias. Ainda que as experiências de reforma agrária e de luta pelo acesso à terra sejam fortemente diferenciadas no tempo, no espaço e nos contextos econômicos, políticos, sociais e culturais nos quais foram geradas, o artigo procurou demonstrar que os resultados da reforma agrária devem ser compreendidos numa abordagem mais ampla do desenvolvimento (social, sustentável etc.) onde pesam variáveis como a conquista de autonomia por parte das famílias beneficiárias, a melhoria nas condições de vida (apesar das precariedades encontradas), o reconhecimento dos direitos 
de um conjunto variado de atores relacionados à terra e aos recursos naturais, bem como a presença das mulheres nesse cenário.

Apesar das previsões em contrário, a reforma agrária reassumiu uma posição de destaque no debate, nos processos sociais, nas atividades políticas e em alguns programas governamentais no período recente, apresentando-se como uma oportunidade concreta na estratégia de reprodução social de uma parcela não desprezível de famílias camponesas e de trabalhadores que habitam o meio rural do planeta, em particular aqueles situados nos países latino-americanos. Consultando os dados estatísticos, particularmente aqueles referentes aos países em desenvolvimento, ou mesmo examinando alguns eventos que pautaram a agenda dos últimos 10 anos, veremos que a suposta obsolescência da reforma agrária está longe de ser levada a cabo, além do fato de que as questões colocadas em torno do tema não traduzem necessariamente uma visão nostálgica do passado, mas, ao contrário, contribuem para o redimensionamento da questão agrária e sua relação com as transformações sociais. O contexto latino-americano atual, no momento em que a FAO/ONU realiza sua segunda conferência específica sobre o tema (ICARRD - Conferência Internacional sobre Reforma Agrária e Desenvolvimento Rural), diferentemente daquele observado nos anos 80, época da WCARRD, descortina algumas possibilidades de processos e políticas que permitam a conjugação entre distribuição de ativos fundiários, crescimento econômico e desenvolvimento social.

\section{Referências bibliográficas}

AMIN, S. (2005). Les luttes pour la terre et les ressources naturelles et la construction d'alternatives. Foro Mundial sobre la Reforma Agraria, Valencia.

ANAND, S.; KANBUR, S.M.R. (1998). Inequality and development: a critique. Journal of Development Economics, Jun., 41(1) pp.19-43.

ARCAND, J.L. (2000). Malnutrition and growth: The efficiency cost of hunger. Rome: Policy Analysis Division of the Food and Agriculture Organization of the United Nations (FAO, ESAE). 
BENABOU, R. (1997). Inequality and growth. In: Bernarke, B.; Rotemberg, J. (eds). NBER Macroeconomics annual. Cambridge: MIT Press, pp. 11-74.

BINSWANGER, H.; DEININGER, K.; FEDER, G. (1995). Power, distortions, revolt and reform in agricultural land relations. In: BEHRMAN, J., SRINIVASAN, T. (eds.) Handbook of Development Economics. v. III, Amsterdam: Elsevier.

BIRDSALL, N.; LONDONO, J.L. (1997), Asset inequality matters: an assessment of the World Bank's approach to poverty reduction. American Economic Review, vol. 87(2), pp. 32-37.

BIRDSALL, N.; ROSS, D.; SABOT, R. (1995). Inequality and growth reconsidered: lessons from East Asia. World Bank Economic Review, 9 (3), pp. 477-508.

BORRAS Jr., S., KAY, C., LODHI, A. (2005). Agrarian reform and rural development :historical overview and current issues. ISS/UNDP Land, poverty and public action - policy paper n.1.

BORRAS Jr., S. (2006). The Philippine land reform in comparative perspective: some conceptual and methodological implications. Journal of Agrarian Change, v. 6., n.1, jan.

CHONCHOL, J. (2005). Globalización, pobreza y agricultura familiar en America Latina. Foro Mundial sobre la Reforma Agraria, Valencia.

COX, M.; MUNRO-FAURE, P.; MATHIEU, P., HERRERA, A.; PALMER, D.; GROPPO, P. (2003). FAO in Agrarian Reform. Land Reform, Land Settlement and Cooperatives, Roma, 2003/2.

DE JANVRY, A.; SADOULET, E. (1999). Growth, poverty and inequality in Latin American: a causal analysis - 1970-1994. Conference on Social Protection and Poverty. Inter-American Development Bank. Washington: fév.

DE JANVRY, A.; SADOULET, E. (2001). La inversión en desarrollo rural es buen negocio. In: Echeverría, R. (ed.) Desarrollo de las economías rurales en America Latina y el Caribe. Washington: BID.

DE JANVRY, A.; SADOULET, E. (2002). Land reform in Latin American: ten lessons toward a contemporary agenda. World Bank's Latin American Land Policy Workshop. Pachuca, Mexico: jun. 
DE JANVRY, A.; SADOULET, E. (2005). Access to land and development. New Palgrave Dictionary of Economics. 2a. ed. Palgrave Macmillan.

DEININGER, K.; SQUIRE, L. (1996). A new dataset measuring income inequality. World Bank Economic Review, 10 (2), pp. 565-591.

DELGADO, G., CARDOSO Jr., J. C. (orgs.) (2000). A universalização de direitos sociais no Brasil : a Previdência Rural nos anos 90. Brasília: IPEA.

EL GHONEMY, M.R. (2005). Agrarian reform and rural development: post-WCARRD challenges and limitations. Rome: FAO/ONU.

FAO (2001). The role of agriculture in the development of LDCs and their integration into the World Economy. Third United Nations Conference on the Least Developed Countries. Bruxelles, 14.05.2001.

FAO (2004). An approach to rural development: participatory and negotiated territorial development. Rome: Rural Development Division.

FEI, J.; RANIS, G.; KUO, S. (1979). Growth with equity: the Taiwan case. New York: Oxford University Press.

FURTADO, C. (1998). O capitalismo global. Rio de Janeiro: Paz e Terra. GARCÉS, V. (2005). El Foro Mundial sobre la Reforma Agraria. Foro Mundial sobre la Reforma Agraria, Valencia.

GUANZIROLI, C. (1998). Reforma agrária e globalização da economia: $o$ caso do Brasil. FAO (Cooperação FAO/Incra).

HAZELL, P.B.R. ROELL, A. (1983). Rural growth linkages: household expenditure patterns in Malaysia and Nigeria. International Food Policy Research Institute Research Report 41, Washington.

HEREDIA, B.; MEDEIROS, L.; PALMEIRA, M.; CINTRAO, R.; LEITE, S. (2005). Regional impacts of land reform in Brazil. Land reform, land settlement and cooperatives. FAO/ONU. Roma. 2005/1, p. 20-34.

HIRSCHMAN, A. O. (1984). Getting ahead collectively. New York : Interamerican Foundation.

HIRSCHMAN, A. O. (1994). La conéxion intermitente entre el progreso político y económico. Estudios Públicos, 56, primavera, p.5-14. 
Reforma agrária e desenvolvimento na América Latina:

rompendo com o reducionismo das abordagens economicistas

KHAN, A. R.; MUQTADA, M. (1997). Employment expansion and macroeconomic stability under increasing globalization. Londres: Macmillan.

KUZNETS, S. (1955). Economic growth and income inequality. The American Economic Review, Mar., 45(1): 1-28.

LEITE, S. (2000). Impactos regionais da reforma agrária no Brasil: aspectos políticos, econômicos e sociais. In: LEITE, P.S (ed.) Reforma Agrária e Desenvolvimento Sustentável. Brasília: Paralelo 21.

LEITE, S. (2004). Autoconsumo y sustentabilidad en la agricultura familiar: una aproximación a la experiencia brasileña. In: Belik, W. (ed.) Politicas de seguridad alimentaria y nutrición en America Latina. São Paulo: Hucitec.

LEITE, S.; HEREDIA, B.; MEDEIROS, L.; PALMEIRA, M.; CINTRAO, R. (2004). Impactos dos assentamentos: um estudo sobre o meio rural brasileiro. São Paulo/ Brasília: Ed. Unesp/ Nead.

LIPTON, M. (2001). Rural poverty reduction: the negelected priority. International Fund for Agricultural Development's Report on Rural Poverty.

LUND, P.; HILL, G. (1979). Farm size, efficiency and economies of size. Journal of Agriculture Economics. Mai., 30(2) pp 145-158.

MAZOYER, M.; ROUDART, L. (2002). Histoire des agricultures du monde: du néolithique à la crise contemporaine. Paris: Seuil.

MEDEIROS, L., DEERE, C. (2005). Agrarian reform and poverty reduction: lessons from Brazil. ISS/UNDP Land, poverty and public action - policy paper n.2.

MEDEIROS, L., LEITE, S. (orgs.) (2004). Assentamentos rurais, mudança social e dinâmica regional. Rio de Janeiro: Mauad.

MELLOR, J.W. (2001). Agricultural development: so many successes, such excellent results. Rome: Food and Agriculture Organization of the United Nations.

MOYO, S. (2005). Land question and land reform in southern Africa. RSA Land Summit, Soweto, ago.

SARACENO, E. (2001). La experiencia europea de desarrollo rural y su utilidad para el contexto latinoamericano. Bruxelles: Comission Européenne. 
SARRIS, A. (2001). O papel da agricultura no desenvolvimento econômico e na diminuição da pobreza: uma base empírica e conceitual. NEAD.

SEN, A. (2000). Desenvolvimento como liberdade. São Paulo: Cia. das Letras.

STIGLITZ, J. (2000). Distribuição, eficiência e voz: elaborando a segunda geração de reformas. In: Teófilo, E. (org.) Distribuição de riqueza e crescimento econômico. Brasília: NEAD.

TAVARES, M. C. (1996). A questão agrária e as relações de poder no país. Folha de São Paulo. São Paulo, p.5.

VEIGA, J.E. (1998). Pobreza rural, distribuição de renda e crescimento: a experiência brasileira. Conferência Internacional sobre Distribuição de Riqueza, a Pobreza e o Crescimento Econômico, Brasília.

VEIGA, J.E. (2001). O desenvolvimento territorial no Brasil: do entulho varguista ao zoneamento ecológico-econômico. Encontro ANPEC 2001. Salvador: ANPEC.

Recebido em maio de 2006 e revisto em janeiro de 2007. 